Departamento de Patologia e Clínica Médicas (2. ${ }^{\mathrm{a}}$ cadeira) Diretor: Prof. contratado Dr. Romeu Diniz Lamounier

\title{
OBSERVAÇÕES PRELIMINARES SOBRE A HEMOSEDIMENTAÇÃO EM BOVINOS PELO MÉTODO DE WESTERGREN
}

\section{Romeu D. Lamounier e Paulo de Carvalho Pereira Assistente}

A hemosedimentação em animais domésticos aparece com o veterinário francês Césari, em 1913 (citado por BARBIER e al) ( ${ }^{1}$ ) fazendo observações sôbre anemia do cavalo e dando uma técnica para a hemosedimentação $\left({ }^{2}\right)$, técnica que foi modificada mais tarde.

A seguir, segundo RoDRiguez $\left({ }^{3}\right)$, e MAREK $\left({ }^{4}\right)$, foi estudada na anemia infecciosa do cavalo e as escolas de veterinária de Berlin e Viena demonstram não ser especifica a hemosedimentação. Refere também RoDRIGUEz que HUERTA e IGUAL estudam essa prova na durina e no morno.

Depois dêstes trabalhos, maior número de observações foram feitas e melhores técnicas adotadas na hemosedimentação do cavalo; assim Dukes $\left({ }^{5}\right)$ cita trabalho de Hammersland e colaboradores que acharam como média normal de sedimentação $18 \mathrm{~mm}$. por hora, enquanto que em cavalo com anemia infecciosa a média foi de $26 \mathrm{~mm}$.. Simms, também citado pelo mesmo autor, considera 1 a $4 \mathrm{~mm}$. por hora, como normais em cães, enquanto que na cinomose, em envenenamento por Salmon e na prenhês a hemosedimentação aumenta.

Outras espécies como a caprina, ovina e bovina foram objeto de menor estudo e acreditamos que o principal motivo seja a lentidão da hemosedimentação nestas espécies. FERguson $\left(^{6}\right)$ estudou a sedimentação em vacas e encontrou como média normal $2,3 \mathrm{~mm}$. em 7 horas, tendo considerado $4 \mathrm{~mm}$. como patológico; ao mesmo tempo assinalou o possível valor prático da hemosedimentação, facilitando o diagnóstico e o prognóstico, em doenças de bovinos.

Em ovinos, Holman $\left({ }^{7}\right)$, fazendo estudos hematológicos, refere-se à hemosedimentação, pelo aparêlho descrito por SHUFfLEBotTom.

\section{NOSSAS OBSERVAÇÕES}

Nosso trabalho tem por objetivo evidenciar a importância da hemosedimentação em bovinos e indicar sua possível aplicação prática como meio semiológico; adotamos o aparêlho de Westergren, de uso corrente na hemosedimentação humana. Respeitamos sempre os cui- 
dados técnicos indicados por Kolmer $\left({ }^{8-9}\right)$, Corona $\left({ }^{10}\right)$, Fisher $\left({ }^{11}\right)$ e KraCKe ( ${ }^{12}$ ) e controlamos o número de hematias o qual, em nossas provas, apresentou uma variação de 5.000 .000 a 9.540 .000 por milímetro cúbico de sangue, com uma única excepção em que encontramos 16.340.000 (animal n. ${ }^{\circ} 3$ ).

A temperatura da sala, durante as provas foi mantida entre mínima $16,5^{\circ} \mathrm{C}$. e máxima de $25,5^{\circ} \mathrm{C}$.

A aglutinação rápida para brucelose foi negativa em todos os casos.

As leituras foram feitas na $1 .^{\mathrm{a}}, 6 .^{\mathrm{a}}, 12 .^{\mathrm{a}}, 24 .^{\mathrm{a}}$, horas após o início da prova como se vê no quadro I.

QUADRO I

Hemosedimentação em bovinos normais

\begin{tabular}{|c|c|c|c|c|c|}
\hline \multirow{3}{*}{$\begin{array}{c}\text { Animal } \\
\text { N. }\end{array}$} & \multirow{3}{*}{$\begin{array}{l}\text { Tempo decorrido } \\
\text { após a colheita do } \\
\text { sangue }\end{array}$} & \multicolumn{4}{|c|}{ Horas e Leituras } \\
\hline & & $1 .^{\mathrm{a}}$ & $6 .^{\mathrm{a}}$ & $12 .^{\mathrm{a}}$ & $24 .^{\mathrm{a}}$ \\
\hline & & $\mathrm{mm}$. & $\mathrm{mm}$. & $\mathrm{mm}$. & $\mathrm{mm}$. \\
\hline \multirow{6}{*}{$1(*)$} & Logo após & 0 & 0 & - & 2 \\
\hline & 1 hora & 0 & 0 & - & 2 \\
\hline & 2 horas & 0 & 0 & - & 2 \\
\hline & 3 horas & 0 & 0 & - & 2 \\
\hline & 4 horas & 0 & - & 一 & 2 \\
\hline & 6 horas & 0 & 1 & 1 & 2 \\
\hline \multirow{2}{*}{2} & Logo após & 0 & 0 & 1 & 1 \\
\hline & 6 horas & 0 & 0 & 1 & 1 \\
\hline \multirow{2}{*}{3} & Logo após & 0 & 0 & 0 & 1 \\
\hline & 6 horas & 0 & 0 & 1 & 1 \\
\hline \multirow{2}{*}{4} & Logo após & 0 & 0 & 1 & 2 \\
\hline & 6 horas & 0 & 0 & 0 & 2 \\
\hline 5 & 6 horas & 0 & 1 & 3 & 3 \\
\hline
\end{tabular}

(*) Para êste animal uma segunda hemosedimentaç̌̃o realizada em temperatura ambiente mais elevada, acusou uma leitura de $3 \mathrm{~mm}$. em 24 horas (ver adiante).

Procuramos determinar quanto tempo, após a colheita de sangue a hemosedimentação poderia ser iniciada sem apresentar uma modificação significativa ao fim da vigesima quarta hora, pois consideramos que o tempo decorrido após a colheita de sangue e o início da prova é um fator de grande importância prática, fundamental em veterinária, porque em rarissimas ocasiões pode-se iniciar as provas imediatamente após a colheita da amostra de sangue, principalmeñte na clínica de bovinos, quase sempre realizada em pontos mais ou menos distantes e sem recursos de laboratório. 
As provas com o animal $n .^{\circ} 1$ (vaca), que clinicamente nada apresentava de anormal capaz de influenciar sôbre a sedimentação sangüinea, mostraram que a sedimentação iniciada após, uma, duas, três, quatro e seis horas depois da colheita do sangue deram leitura constante de $2 \mathrm{~mm}$. ao fim da vigésima quarta hora.

$\mathrm{O}$ animal $n .^{\circ} 2$, novilha clinicamente sã, nas provas realizadas imediatamente depois e com seis horas após a colheita do sangue, deu a mesma taxa de sedimentação ou seja $1 \mathrm{~mm}$..

Os três seguintes casos: o n. ${ }^{\circ} 3$, um tourinho; o n..$^{\circ} 4$, um bovino adulto, castrado comportaram-se do mesmo modo; assim como o n. ${ }^{\circ} 5$, vaca que pela anamnese sugeria um processo do aparêlho locomotor, porém o nosso exame clínico nada revelou de anormal no dia da colheita do sangue para a hemosedimentação e realmente a taxa de sedimentação sangüinea se enquadra perfeitamente dentro da normalidade dos nossos casos.

Com estes poucos casos parece não haver modificação apreciável na hemosedimentação de bovinos executando a prova seis horas após a colheita de sangue.

Em uma de nossas provas tivemos ocasião de observar (com o animal $n .^{\circ} 1$ ), variações na taxa de hemosedimentação possivelmente devidas apenas à temperatura ambiente, pois com mínima de $19^{\circ} \mathrm{C}$. e máxima de $24^{\circ}$ C. a taxa foi de $3 \mathrm{~mm}$. e de $2 \mathrm{~mm}$. com mínima de $16,5^{\circ}$ C. e máxima de $20,5^{\circ}$ C., ao fim de $24^{\mathrm{a}}$ hora. E' certo entretanto que a diferença foi muito pequena, considerando o número absoluto.

A cifra encontrada por nós nestes casos normais foi muito baixa, mas evidentemente seria de se indagar se as modificações patológicas poderiam ter um real significado. O quadro II esclarece essa pergunta.

QUADRO II

Hemosedimentação em casos patológicos de bovinos e gestação

\begin{tabular}{|c|c|c|c|c|}
\hline \multirow{2}{*}{$\underset{\mathrm{N} .^{\circ}}{\text { Animais }}$} & \multicolumn{3}{|c|}{$\begin{array}{l}\text { Leitura em mm. ao } \\
\text { fim da } 24 .^{a} \text { hora }\end{array}$} & \multirow[t]{2}{*}{ Observações } \\
\hline & $1 .^{\mathrm{a}}$ & $2 .{ }^{n}$ & $3 .{ }^{\mathrm{n}}$ & \\
\hline 29 & 4 & - & - & Mamite e Metrite \\
\hline 28 & 6 & 12 & - & Vaginite e lesões podais \\
\hline 23 & 9 & - & - & Metrite \\
\hline 22 & 4 & - & - & Gestação - último período \\
\hline 16 & 3 & 8 & 8 & Mamite \\
\hline 26 & 12 & - & - & Mamite \\
\hline 27 & 7 & - & - & Mamite \\
\hline S/ N. ${ }^{\circ}$ & 5 & - & - & Cardiopatia e Nefropatia \\
\hline
\end{tabular}


Animais, portadores de processos patológicos diversos, apresentaram uma hemosedimentação significativa com a leitura ao fim da $24 .^{a}$ hora, sendo iniciada a prova 6 horas após a colheita do sangue:

ANIMAL N. ${ }^{\circ} 29$ : vaca com mamite crônica e metrite purulenta crônica, não apresentou uma hemosedimentação significativa em 24 horas, isto é foi apenas $4 \mathrm{~mm}$.

Animal N.$^{\circ}$ 28: vaca com vaginite crônica e lesões necróticas extensas nos 4 espaços interdigitais (frieira) e em franca evolução como tivemos oportunidade de observar com nossas sucessivas visitas; êste animal apresenta um aumento sensível na hemosedimentação: assim, em datas diferentes, apresentou $6 \mathrm{~mm}$. e $12 \mathrm{~mm}$.

ANimal N. ${ }^{\circ} 23$ : vaca com metrite, cuja hemosedimentação foi de $9 \mathrm{~mm}$., taxa bastante significativa.

ANIMAL N. ${ }^{\circ} 22$ : vaca no período final de gestação que revelou um aumento mínimo, dando $4 \mathrm{~mm}$. em 24 horas.

ANIMAL N. ${ }^{\circ} 16$; esta vaca constitue um exemplo bem evidente de que a hemosedimentação tem valor semiológico na evolução de casos clínicos: a $1 .^{\mathrm{a}}$ prova deu apenas $3 \mathrm{~mm}$., com o sangue colhido no dia em que o animal apresentou uma diminuição sensível na produção de leite e nossos exames, clínico e de laboratório, não revelaram mamite, embora o leite tenha apresentado uma reação alcalina; mais tarde, uma nova prova deu $8 \mathrm{~mm}$. e os exames clínicos e de laboratório revelaram uma mamite aguda e uma outra prova feita algum tempo depois, ainda apresentava hemosedimentação de $8 \mathrm{~mm}$. na $24 .^{\mathrm{a}}$ hora, demonstrando que o processo se manteve estacionário.

Acreditamos assim que da primeira vez a prova foi realizada no momento inicial do processo de mamite e nas outras vezes as provas coincidiram com o processo em evolução.

ANIMAIS N.os 26 e 27: são vacas representando casos de mamite clínicamente crônicos e revelaram 12 e $7 \mathrm{~mm}$. respectivamente.

ANimal $\mathrm{S} / \mathrm{N} .^{\circ}$ : é uma vaca, retirada de um rebanho em que exames "post-mortem" parecem sugerir o diagnóstico de "Entéqué", êste animal, ao exame clinico por nós feito, revelou uma cardiopatia, possivelmente uma miocardite $\mathrm{e}$ uma nefropatia provàvelmente uma hidronefrose, além de numerosoș abcessos cutâneos conseqüentes à infecções bacterianas sôbre pontos previamente lesados por larvas de Dermatobia; este animal apresentou $5 \mathrm{~mm}$. ao fim da $24 .{ }^{\mathrm{a}}$ hora.

Devemos mencionar uma possível causa de êrro nas provas de hemosedimentação quando os animais estão sujeitos a tratamento com injeções endovenosas de solução hipertônica de glicose, assim: um bezerro, com diagnóstico de necrobacilose, teve sua hemosedimentação, 
feita antes de qualquer medicação, igual a $4 \mathrm{~mm}$. em 24 horas; não consideramos normal êsse resultado embora não tenhamos provas em bezerros normais, mas sabe-se que a hemosedimentação é quase sempre menor nos jovens; além disso êste mesmo animal, mais tarde, quando pràticamente curado, deu apenas $2 \mathrm{~mm}$., administrando $20 \mathrm{~cm}^{3}$ de solução de glicose a $50 \%$, endovenosamente, durante 10 dias e colhendo sangue 12 horas após a última injeção verificou-se uma sedimentação de $5 \mathrm{~mm}$. e deixando de administrar a solução de glicose durante 7 dias observamos apenas $2 \mathrm{~mm}$. em 24 horas.

Seria de se indagar qual o tempo necessário para o retorno da hemosedimentação à normalidade, após a última administração de glicose hipertônica e se outras soluções, também hipertônicas, manifestam o mesmo efeito.

\section{RESUMO}

Em observações preliminares os A.A. encontram 1 a $3 \mathrm{~mm}$. como taxa de hemosedimentação normal nos bovinos, pelo aparêlho de WESTERGREN.

A hemosedimentação iniciada 6 horas após a colheita de sangue não traz uma modificação significativa na leitura ao fim da $24 .^{a}$ hora.

Mostram os A.A. modificações da hemosedimentação em alguns casos patológicos e de gestação além da provável influência de solução hipertônica de glicose, quando administrada aos animais antes da colheita do sangue.

\section{SUMMARY}

In preliminary tests the authors, using WESTERGREN's apparatus, found 1 to $3 \mathrm{~mm}$. as normal rate of blood sedimentation for cattle.

The blood sedimentation, begun 6 hours after the collection does not bring any change of importance in the result of test reading after the 24th hour.

The A.A. point out changes of blood sedimentation in some pathologic and pregnancy cases, besides probable influence of hipertonic solution of glucose when administered to the animals before the collection of blood.

\section{BIBLOGRAFIA}

1 - Barbier, J. - Piquet, G. - 1936 - La recherche de la vitesse de sédimentation sanguine en pratique médicale courante. Clin. Lab., 15 (4) : 82-9

2 - Monvorsin, A. - Moussu, R. - 1929 - Précis de diagnostic vétérinaire. Paris, Vigot frères

3 - Rodríguez, T. - 1935 - Exploración clinica de los animales domésticos, Barcelona, Editorial Labor S. A. 
4 - Hutyra, F. - MareK, J. - Manninger, R. - 1938 - Special Pathology and therapeutics of the diseases of domestic animals, 3,4 th. ed. London, Ballière, Tindall \& Cox

5 - Dukes, H. H. - 1943 - The physiology of domestic animals. 5 th. ed. Ithaca, Comstock Publishing Company, Inc.

6 - Ferguson, L. C. - 1937 - Studiens on bovine blood. I. The sedimentation rate and percentage volume of erythrocytes in normal blood. Jour. Amer. Vet. Med. Ass., $91:$ 163-75

7 - Holman, H. H. - 1944 - Studiens on haematology of sheep. I : The blood picture of healthy sheep. Jour. Comp. Path., 54: 26-40 $2 .^{a}$ ed. Rio de Janeiro, Editora Guanabara

8 - Kolmer, J. A. - Boerner, F. - 1939 - Téenica de laboratório. Trad.

9 - Kolmer, J. A. - 1943 - Clinical diagnosis by laboratory examinations. New York, D. Appleton Century Company, Inc.

10 - Corona T., Leonidas - 1940 - Química normal y patológica de la sangre. $2{ }^{a}$ ed. Santiago de Chile, Ediciones Ercilla S. A.

11 - Fisher, A. - 1942 - Laboratório. - Trad. 2. ${ }^{\mathrm{a}}$ ed. argentina. Rio de Janeiro, Editora Guanabara. (Biblioteca de Semiologia, T. Padilla e P. Cossio, vol. 10)

12 - Kracke, R. - 1943 - Doenças do sangue e atlas de hematologia. Trad. $2{ }^{a}$ ed. Rio de Janeiro, Editora Guanabara 